\title{
UNILATERAL ETHMOIDAL POLYPS
}

\section{DR. MUHAMMAD SAEED}

Associate Professor ENT

Punjab Medical College

Allied Hospital Faisalabad.

ABSTRACT:- Objectives: To know the etiology and incidence of unilateral ethmoidal polyps. Design: Descriptive. Setting: ENT department Allied Hospital Faisalabad. Period: From Jan 2007 to June 2009. Material and Methods: The patients were admitted through ENT out patient department. The data was collected on the basis of history, physical examination, investigations, management and follow up. Results: Out of 200 patients between 05 years to 60 years of age suffering from ethmoidal polyps the incidence of unilateral ethmoidal polyps was $35 \%$ and that of bilateral ethmoidal polyps was $65 \%$. The $57 \%$ of patients having unilateral ethmoidal polyps were male and $43 \%$ female. The highest incidence of unilateral ethmoidal polyps was seen during second decade of life $43 \%$. The incidence of unilateral ethmoidal polyps and bilateral ethmoidal polyps was 1.6 and 03 cases per month respectively. The most common presenting symptom was unilateral nasal obstruction $(100 \%)$ in cases of unilateral ethmoidal polyps. The most common associated disease in patients with unilateral ethmoidal polyps was deflected nasal septum (71\%). Transantral ethmoidectomy was carried out in majority of patients (43\%). The most common etiology held to be responsible for unilateral ethmoidal polyps was Vasomotor rhinitis (57\%). Conclusions: The unilateral ethmoidal polyps are not uncommon in young adults and the etiological factors are same as that for bilateral ethmoidal polyps.

Key words:Unilateral ethmoidal polyps, Vasomotor rhinitis, Allergic rhinitis.

\section{INTRODUCTION}

The word polyp comes from Greek though it was later onLatinized which means many footed (polypous).Nasal polyps are swellings of the sino-nasal mucosa. Initially all polypoidal conditions were grouped to gather until histological classification helped to differentiate them from neoplastic conditions ${ }^{1}$. Nasal polyp tissue have a large amount of histamine and have eosinophil infiltration'. Nasal polyps of patient with allergic rhinitis or asthma frequently recur after polypectomy ${ }^{3}$. Recurrent nasal polyps are one of the major leading problem among nasal disease in all developing countries that equally affects all the racial and socio-economical groups with a little preponderance in male ranging $2: 1$ to $4: 1^{4}$. Ethmoidal polyps are more common in asthmatics and rural inhabitants ${ }^{3}$. It is observed that between 1 in 1000 of the children and 20 in 1000 of the adult population would have ethmoidal polyps once or more in their lives ${ }^{4}$. The environmental and social trends significantly influence its prevalence and mode of presentation ${ }^{5}$.The association of ethmoidal polyps with allergic rhinitis, vasomotor rhinitis and childhood asthma have been documented ${ }^{3}$.The rate of recurrence is variable and different studies show that just over $40 \%$ present for the first time and $5 \%$ had five or more polypectomies ${ }^{6}$. Ethmoidal polyps appear as soft, smooth masses, translucent, white and opaque, yellowish or pink in colour and occasionally fleshy ${ }^{7}$. Histological examination shows edema of submucosa and infiltration with eosinophils and round cells .

There is significant relationship between the eosinophils infiltration of nasal polyps and local lgE production ${ }^{2}$. The exact etiology is not known but different theories put forward regarding development of ethmoidal polyps are Bernouilli phenomenon, Polysacharide changes, vasomotor imbalance ${ }^{8}$, Infection ${ }^{9,10,11}$ and Allergy $y^{2,12,13,14}$.

Clinically the patient of ethmoidal polyps present with nasal obstruction, hyposmia, postnasal drip. On examination the nasal patency is reduced, hyposmia or anosmia, the polyps are always visible on anterior rhinoscopy as pearly white multiple grape like masses, in certain cases there might be proptosis or hypertelorism. In addition to general investigations the special investigations required are plain radiology, MRI and CAT scan of nose and paranasal sinusis. The nasal polyps are to be differentiated from neoplasia and hypertrophic turbinates. Treatment of recurrent ethmoidal polyps comprises of both medical and surgical modalities. The medical modalities includes local and systemic Antihistamines and local steroids ${ }^{15,16}$. Among the surgical modalities various surgical procedures are used 
depending upon the extent and recurrence of polyp are nasal polypectomy ${ }^{17}$, nasal polypectomy with intranasal ethmoidectomy ${ }^{18,19,20,21,22,23}$, transantral ethmoidectomy $^{24,25}$, external ethmoidectomy and FESS (functional endoscopic sinus surgery) ${ }^{26}$.

\section{MATERIALAND METHODS}

It was a descriptive study conducted upon 200 patients suffering from ethmoidal polyps in the department of ENT Allied Hospital Faisalabad from Jan 2007 to June 2009.The patients were admitted and detailed history, clinical examination, routine investigations and special investigations were carried out to assess the extent of polyps. Standard Performa was prepared dually filled for each patient. Only those patients were included in study who were suffering from ethmodal polyps and were available for follow up and those patients who were unfit for surgery and patients of antrochonal polyp were excluded from study. The follow up of cases was carried out from 6 months to 24 months. The surgical modalities used were nasal polypectomy, intranasal ethmoidectomy, trans antral ethmoidectomy and external ethmoidectomy.

\section{RESULTS}

Out of 200 patients between 05 years to 60 years of age suffering from ethmoidal polyps the incidence of unilateral ethmoidals polyp was $35 \%$ and that of bilateral ethmoidal polyps was $65 \%$. The $57 \%$ of patients having unilateral ethmoidal polyps were male and $43 \%$ were female. The highest incidence of unilateral ethmoidal polyps was seen during second decade of life $43 \%$. The incidence of unilateral ethmoidal polyps and bilateral ethmoidal polyps was 1.6 and 3 cases per month respectively.

The most common presenting symptom was unilateral nasal obstruction (100\%) in case of unilateral ethmoidal polyps. The most common associated disease in patients with unilateral ethmoidal polyps was deflected nasal septum (71\%). Transantral ethmoidectomy was carried out in majority of patients (43\%). The most common etiology held to be responsible for unilateral ethmoidal polyps was Vasomotor rhinitis (57\%).
Table-I. Distribution of patients with ethmoidal polyps ( $\mathrm{N}=200)$

\section{Distribution}

Bilateral ethmoidal polyps

Unilateral ethmoidal polyps

Total

\section{Table-Il. Age of patients with unilateral ethmoidal polyps ( $\mathrm{N}=70$ )}

\section{Age group}

5-10 yrs

11-20yrs

21-30yrs

$31-40 \mathrm{yrs}$

$41-50 \mathrm{yrs}$

$51-60 \mathrm{yrs}$

\section{No. of patients}

02

30

20

07

05

06 \%age

$03 \%$

$43 \%$

$28 \%$

$10 \%$

$07 \%$

$09 \%$

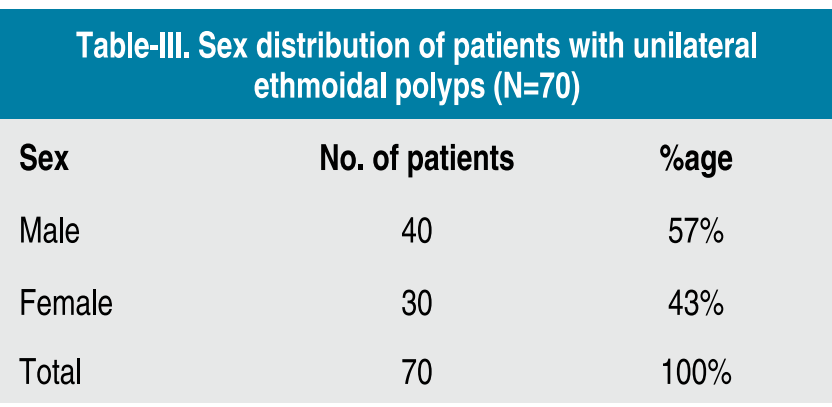

Table-IV. Symptoms of patients with unilateral ethmoidal polyps $(\mathrm{N}=70)$

\begin{tabular}{lcc}
\multicolumn{1}{c}{ Symptoms } & No. of Patients & \%age \\
Unilateral nasal obstruction & 70 & $100 \%$ \\
Unilateral rhinorrhea & 40 & $57 \%$ \\
Post nasal drip & 40 & $57 \%$ \\
Sneezing & 30 & $43 \%$ \\
Headch & 25 & $36 \%$
\end{tabular}




\begin{tabular}{|c|c|c|}
\hline Signs & No. of Patients & \%age \\
\hline Unilateral nasal obstruction & 70 & $100 \%$ \\
\hline Unilateral rhinorrhea & 35 & $50 \%$ \\
\hline Post nasal discharge & 45 & $64 \%$ \\
\hline Hyposmia & 50 & $71 \%$ \\
\hline Unilateral telecantus & 50 & $71 \%$ \\
\hline Proptosis & 30 & $43 \%$ \\
\hline
\end{tabular}

Table-VI. Associated diseases in patients of unilateral ethmoidal polyps $(\mathrm{N}=70)$

\begin{tabular}{lcc}
\multicolumn{1}{c}{ Disease } & No. of Patients & $\%$ age \\
D.N.S & 50 & $71 \%$ \\
$\begin{array}{l}\text { Maxillary + Ethmoidal } \\
\text { sinusitis unilateral }\end{array}$ & 45 & $64 \%$ \\
$\begin{array}{l}\text { Hypertrophied turbinates } \\
\text { bilateral }\end{array}$ & 30 & $43 \%$ \\
\hline
\end{tabular}

Table-VII. Surgical approaches in patients with unilateral ethmoidal polyps $(\mathrm{N}=70)$

$\begin{array}{lcc}\text { Surgical approach } & \text { No. of patients } & \% \text { age } \\ \text { Simple polypectomy } & 05 & 07 \% \\ \begin{array}{l}\text { Nasal polypectomy + } \\ \text { intranasal ethmoidectomy }\end{array} & 15 & 22 \% \\ \text { Transantral ethmoidectomy } & 30 & 43 \% \\ \text { External ethmoidectomy } & 20 & 28 \%\end{array}$

Table-VIII. Etiology of unilateral ethmoidal polyps $(\mathrm{N}=70)$

$\begin{array}{lcc}\text { Etiology } & \text { No. of patients } & \% \text { age } \\ \text { Vasomotor rhinitis } & 40 & 57 \% \\ \text { Allergic rhinitis } & 20 & 28 \% \\ \text { Allergic fungal sinusitis } & 07 & 11 \% \\ \text { Aspirin intolerance } & 03 & 04 \% \\ \text { Cystic fibrosis } & 00 & 00 \%\end{array}$

\section{DISCUSSION}

As per classical teaching ethmoidal polyps are more commonly seen in adults and elderly people and they are usually bilateral. We have bee observing for sometime that unilateral ethmoidal polyps are not that uncommon and more over they are occurring in relatively younger age group. To confirm this observation this study was carried out. Out of 200 patients 70 (35\%) had unilateral ethmoidal polyps and $130(65 \%)$ had bilateral ethmoidal polyps as compare with the study of Muhammad Riaz et al in which it was $16 \%$ and $84 \%$ respectively ${ }^{27}$.

It has been observed that incidence of unilateral ethmoidal polyp is higher in younger age group because $43 \%$ patients were from second decade and $28 \%$ were from third decade of life as compare with $9 \%$ of patients belonging to sixth decade of life. The incidence was higher in males ${ }^{27,30}$.

The etilogy of unilateral ethmoidal polyps was vasomotor rhinitis in 40 (57\%) allergic rhinitis in 20 (28\%), Allergic Fungal sinusitis 07 (11\%), Aspirin intolerance 03 (04\%), Neoplasm , bacterial rhino sinusitis , cystic fibrosis were not encountered in any case as compare to the study of Muhammad Riaz et al in which the etiological factors were vasomotor rhinitis (59\%), allergic rhinitis (18.5\%), Allergic Fungal sinusitis (14\%) Aspirin intolerance (4\%), cystic fibrosis $(0 \%)$ respectively ${ }^{27}$.

Which shows that the most common factor responsible for the development of ethmoidal polyps in our and other studies was Vasomotor rhinitis.

In an other study the incidence of vasomotor rhinitis , allergic rhinitis and cystic fibrosis as an etiological factor in the development of ethmoidal polyps was $71.5 \%, 27 \%$, $1.5 \%$ respectively ${ }^{28}$.

According to a study by Monare Vautrin et al the incidence of vasomotor rhinitis in patients of ethmoidal polyps was $60 \%{ }^{29}$.

In the study by A lqbal SI Ali the prevalence of vasomotor rhinitis and allergic rhinitis was $43 \%$ and $33 \%$ as compare with $57 \%$ and $28 \%$ seen in our study respectively ${ }^{30}$. 
Our study shows that the incidence of unilateral ethmoidal polyps in young adults is quite considerable but the etiological factors which are responsible for the causation of unilateral ethmoidal polyps are almost same which are seen in the development of bilateral ethmoidal polyps and out of all these factors the vasomotor rhinitis is the most common.

\section{CONCLUSION}

The unilateral ethmoidal polyps are not uncommon in young adults and the etiological factors are same as seen in bilateral ethmoidal polyps.

Copyright@ 07 Aug, 2010.

\section{REFERENCES}

1. Berdal P. Serological examination of nasal polyp fluid. Acta Otolaryngologica 1954:115.

2. Chandra R.K and Abrol B.M. Journal of Laryngology and otology. 1974:88 1019.

3. Maloney J.R and Collins J. Nasal polyps and bronchial asthma. British Journal of disease of the chest; 1977: 71, $1-6$.

4. Drake-Lee A.B. Nasal polyps; Scott Brown, s Otolaryngology. 1997: New sixth edition;04/10/01

5. Shahid Nasal allergy in Pakistan: Current practice and the need for rationalization Pakistan Journal of otolaryngology; 1998 14:25-26

6. Drakee Lee A.B et al. Clinical symptoms free histamine and IgE in patients with nasal polyps International Archieves of allergy and applied immunology 1982:69 268-271

7. Barnes L. Nasal polyps in surgical pathology of the head and neck. New York Marcel Dekker 1985:Barnes L edPP 403-804.

8. ScottBrown 6th edition 04/10/02 Nasal polyps.

9. Slavin RG et al. Nasal polyps and sinusitis. The CV Mosby.co.1988;1291-1303.

10. Maran AGD Lund VJ. Infection and neoplastic disease. Rhinology;1990;95.

11. Iqbal Saqulain G Jalisi M. Nasal polyposis and fungal sinusitis Pak .J. Otolaryngology 1989;9:1973-176.

12. Drake-Lee $A B$ Cehvreton E. Lowe D. The effect of different fixations on the distribution and numbers of mast cells in patients with nasal polyps. J of Laryngology and otology 102;1099-1101.1998.

13. Drake-LeeAB Laughlin P. The release of histamine from nasal polyps tissue and peripheral when challenged with antihuman IgE house dust mite extract and mixed grass pollen extract and compared with positive skin tests. J of Laryngology and otology 102;886-89,1988.

14. Drake-Lee $A B$ et al:1984. Free histamine in in nasal polyp fluid. Rhinology 22:133-8.

15. Chalton R, Machany L, Wilson R, Cole P. Double blind placebo controlled trial of betamethasone nasal drops for nasal polyposis. Brit med J 1985;291:788.

16. Drake Lee AB; Medical treatment of nasal polyps. Rhinology 34;1-4;1994.

17. Eichel BS. The intranasal Ethmoidectomy $\mathbf{A} 12$ year prospective. Otolaryngol-Head Neck-Surg;1982;90: 540-543.

18. Wigand ME. Transnasal ethmoidectomy under endoscopic control. Rhinology 1982;92:1038-41.

19. Yankauer S. Demonstration of intra-nasal surgery on wet. Specimen Laryngoscope 1930:40:642-645.

20. Eichel BS Ethmoiditis Pathophysiology and medical management. Otolaryngol clin North Ann 1985:18;43-53.

21. Morgenstean KM. Intranasal sphenoethmoidectomy antrostomy. Otolaryngol clin North Am 1985:18(1):69-74

22. Eichel BS. Revision spheno ethmoidectomy. Laryngoscope 1985:95:300-304.

23. Friedman WH Katsantosis et al: Sphenoethmoidectomy: The case for ethmoid. Marsupilization Laryngoscope:1986:96:473-479.

24. Schaefer SD Manning. Endoscopic paranasal sinus surgery: Indications and considerations. Laryngoscope 1989;991-5.

25. Mosher HP. The applied anatomy in the intra nasalsurgery of the ethmoid labyrinth. Trans Am Laryngeal Assoc 1912:34:25-39. 
26. Schaefer SD, Manning S, Close LG. Endoscopic paranasal sinus surgery. Indications and contraindications. Laryngoscope 1989; 11:1-5.

27. Muhammad Riaz Akther, Muhammad Ishaque et al. Etiology of nasal polyp. Pakistan J Otolaryngology 2004:20:9-11.

28. Chukuezi AB. Nasal polyposis in a Nigerian district hospital. WestAfr J Med $1994 ; 13(4)$ : 231-3.
29. Moneret Vautrin DA, Hseigh V, Wayoff M et al. Non allergic rhinitis with eosinophilia syndrome a precussor of the triad, nasal Polyposis, intrinsic asthma and intolerance of aspirin. Ann Allergy 1990;64:513-8.

30. A lqbal SI Ali. Vasomotor rhinitis a common cause of nasal polyps. Asnnals Vol 5 No 2 Apr - Jun 1999.
Article received on:

Accepted for Publication:

Received after proof reading:

Correspondence Address:

Dr. Muhammad Saeed

12 B Punjab Medical College Staff Colony

Allied Hospital, Faisalabad

saeedent@ymail.com

\section{$07 / 11 / 2009$}

$07 / 08 / 2010$

$26 / 10 / 2010$
Article Citation:

Saeed M. Unilateral ethmoidal polyps. Professional Med J Dec 2010;17(4):603-607.

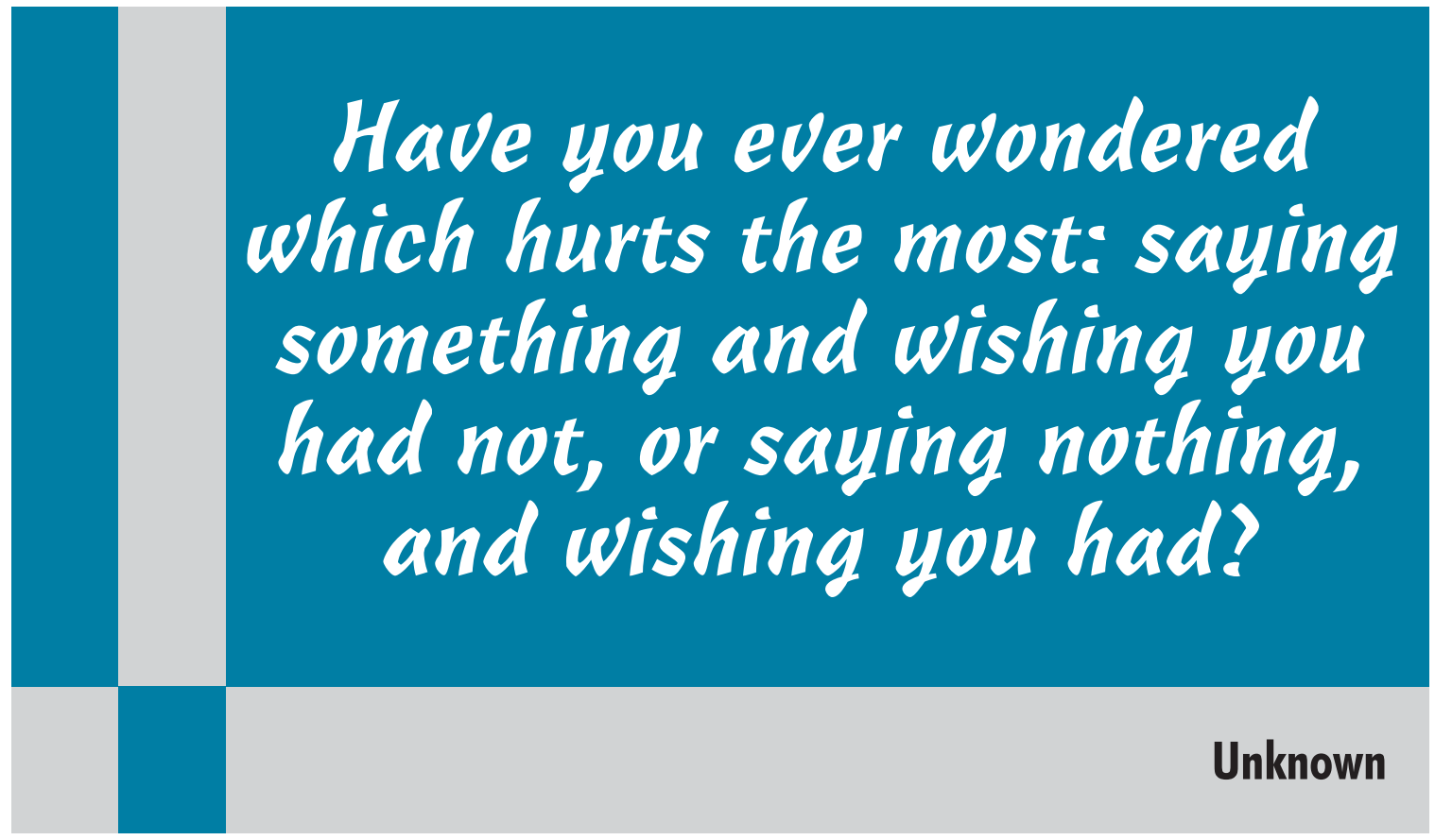

